\title{
Using of building information modeling for existing buildings assessment
}

\author{
Nikolay Garyaev and Fadi Ayoub* \\ Moscow State University of Civil Engineering, Yaroslavskoe shosse, 26, Moscow, 129337, Russia
}

\begin{abstract}
The use BIM technology for new buildings have been proving his efficiency since the technology had established, the efficiency in costs estimation, construction management, resource saving incresed the interest to use BIM for existing building. The researchers covered a wide range of potential benefits for BIM in existing buildings such as: Facilities management, restoration and retrofit planning, deconstruction process, assessment and monitoring, maintenance and energy efficiency. In this paper the use of BIM for estimating the degree of physical deterioration is covered, based on the method included in the literature in Russian federation.
\end{abstract}

\section{Introduction}

Since the BIM technology was established, the interest of construction sector in using BIM had been increasing, and his efficiency had been growing, the major benefits consist in design consistency and visualization time efficiency and cost estimations and clash detection at all stages of the object's life cycle and, resulting resource savings during design, planning and construction stage of new buildings, which motivates the engineering, construction, facility management and other communities to take the benefits of implementing BIM for existing buildings.

BIM implementation in existing buildings faces different challenges associated generally the increased time, effort and knowledge required for BIM use, the lack of construction and operation documentation for existing buildings, the complexity of collecting and organizing the required information about the structure and the installed equipment..etc.. Despite all challenges the researchers have been studying the potential benefits of using BIM for existing buildings such as: Facilities management, restoration and retrofit planning, deconstruction process, assessment and monitoring, maintenance and energy efficiency... The need for existing building assessment, basing on Syrian experience.

Many buildings and structures in Syria during the armed conflict were subjected to varying degrees of destruction. Today, the development of a decision-making mechanism for the restoration, strengthening or demolition of affected structures is becoming an urgent task. The development of this topic will also be relevant for buildings and structures that have been affected by different causes of impairment.

\footnotetext{
${ }^{*}$ Corresponding author: fadi2ayoub@gmail.com
} 
Demolition of any building that shows signs of damage but meets the load-bearing capacity requirements in accordance with design standards is impractical. An important task is to quickly determine the degree of damage to the building and assess the feasibility of its restoration. Based on this, the assessment of the state of the building's load-bearing structures and their load-bearing capacity becomes a priority task when evaluating destroyed structures.

In addition to the present circumstances in Syria, the condition of the structure must be evaluated for many other purposes, such as: determining the reliability of the structure for operation, ensuring the load-bearing capacity of structural elements to perceive approximate loads on them, and checking the strength of the entire structure. Concerns about the proper design and construction of existing structures, including the use of substandard construction materials or poor workmanship, are sometimes enough reasons to conduct an assessment when chips, cracks, and surface deterioration are typical signs of wear.

\section{Materials and methods}

The repair of reinforced concrete structures requires much more attention than may be required in new construction. These considerations arise from the need for an accurate assessment of the state of the structure and the causes of defects and damage or deterioration, the degree of competence required to design repairs, a wide range of technological operations on the construction site, which include highly specialized construction methods and the choice of repair materials and methods. Inspection, maintenance and repair of reinforced concrete structures should be considered simultaneously.

In the light of the above, there is a need to collect available information and data in the field of technical inspection of the building condition and repair of reinforced concrete structures in order to come to a realistic and correct diagnosis of the causes of defects and damage, to provide expert recommendations on the choice of materials and methods of repair.

Before making decision to carry out any repairs, it is necessary to determine the cause of the violation as clearly as possible. Sometimes the cause is obvious, but usually a thorough examination is required. Only then should you choose the repair method. A thorough and logical examination of the current state of the design is the first phase in any rehabilitation project, or reconstruction, the process leading to effective and long-lasting recovery is a diagnosis, prognosis or assessment of the violations, with the subsequent selection of materials and methods of repair, and then prepare the damaged area and applying accepted methods and materials. The successful repair program in the previous main steps is shown in figure 1.

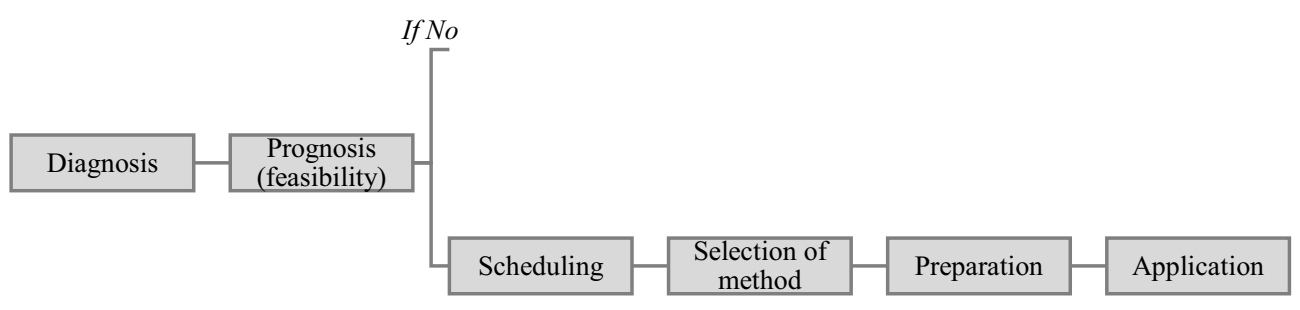

If Yes

Fig. 1. Main stages of the concrete repair program (waddell)

Inadequate design and construction methods often result in concrete structures suffering from a lack of strength, integrity, and operational properties. These conditions can occur at 
any point in the design lifecycle. Definitions and terms are defined by Concrete Society and construction codes. They emphasize and represent the conditions of damage, defect and deterioration of concrete structures under various factors. In General, it can be concluded that these conditions can be broadly classified into defect, damage and deterioration.

Defect (here): Separate non-compliance of structures with any parameter set by the design and technological documentation or regulatory document. SP 349.1325800.2017

Defects often occur in the early stages of a structure's life, and these defects are detected by visual inspection.

Damage (here): A fault received by the structure during manufacturing, transportation, and construction and installation work on the site, as well as during operation, including corrosion damage. SP 349.1325800.2017

usually caused by external mechanical factors during the operation of the structure.

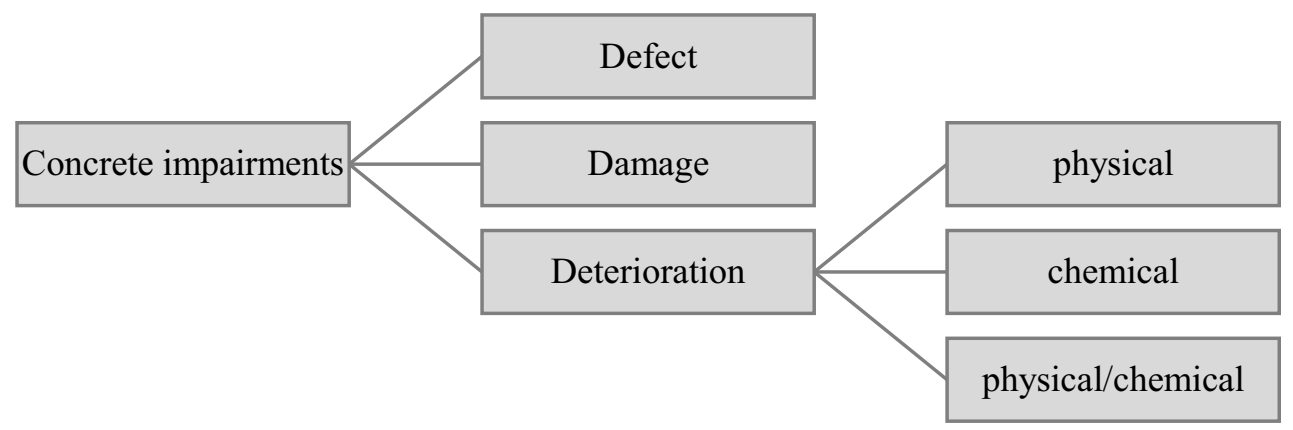

Fig. 2. Types of concrete structures impairments

Deterioration: physical deterioration of the structure, element, and building as a whole should be understood as the loss of their original technical and operational qualities (strength, stability, reliability, etc.) as a result of the impact of natural and climatic factors and human activity. VSN 53-86(P) [1]

There are many methods for assessing the condition of buildings. Analysis of foreign and Russian literature has shown that one of the most popular methods of structures assessment is based on determining the physical deterioration of structural elements and structures, where the physical deterioration is the main indicator for assessing the condition of structures, based on this indicator making decisions for further activities for the rehabilitation or demolition of structures.

The assessment of structural elements or building in general and for selected criteria of assessment (physical deterioration) depends on many factors, the factors to be considered in the assessment process and then in the repair and maintenance of concrete structures figure 3:

Types of structure

Types of design and construction

Types of Structural elements 


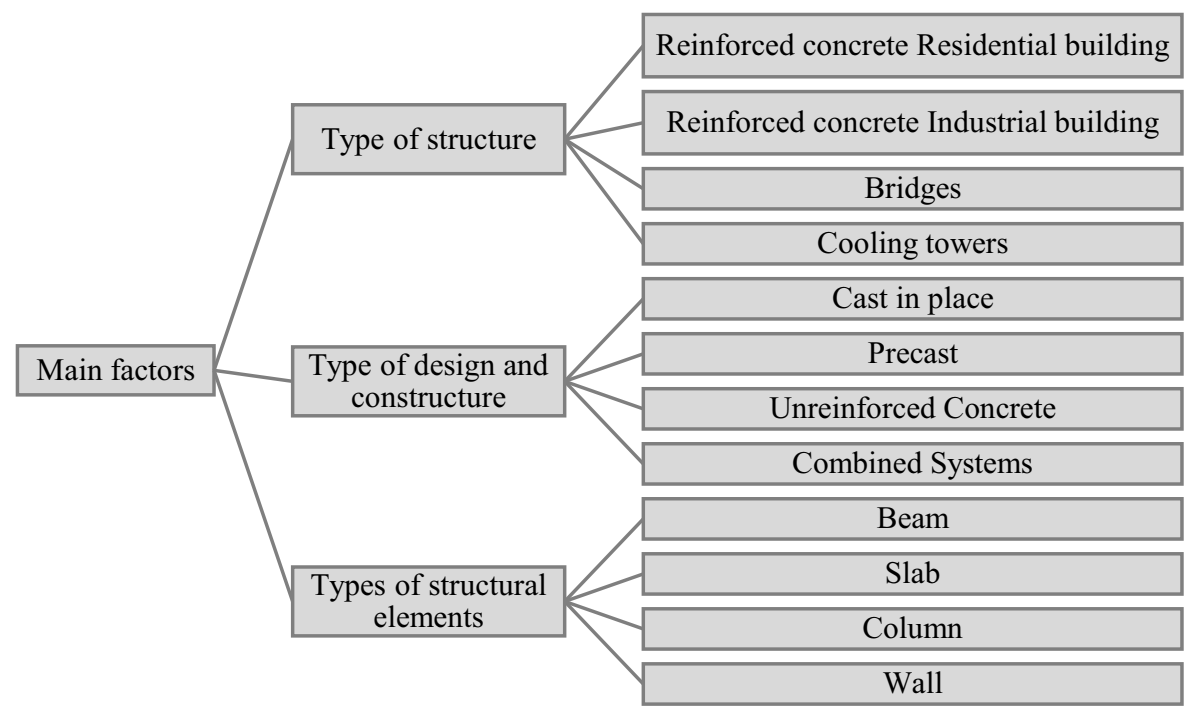

Fig. 3. The factors to be considered in the assessment process

The document, from which the assessment method is selected is dedicated to residential buildings of different materials, in this study the reinforced concrete structures only will be considered.

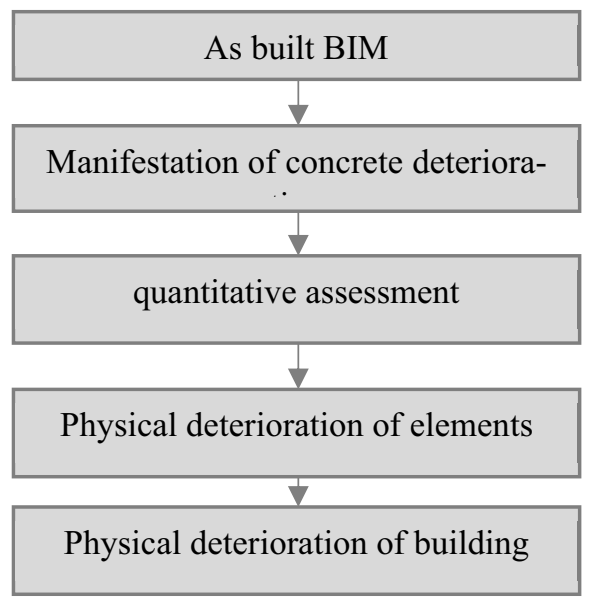

Fig. 4. The process of physical deterioration's estimation

The physical deterioration of a structure, element, or system that has varying degrees of deterioration due to individual sections should be determined by the formula [1]

$$
\Phi_{\mathrm{K}}=\sum_{i=1}^{i=n} \Phi_{i} \frac{P_{i}}{P_{K}}
$$

$\Phi_{\mathrm{K}}$ physical deterioration of the structure, element or system, \%;

$\Phi_{i}$ - the physical wear of a section of a structure, element, or system, \%;

$P_{i}$ - dimensions (area or length) of the damaged area, $\mathrm{m} 2$ or $\mathrm{m}$;

$P_{K}$ - dimensions of the entire structure, $\mathrm{m} 2$ or $\mathrm{m}$;

$\mathrm{n}$ - number of damaged sections. 
The physical deterioration of a building should be determined by the formula [2]

$$
\Phi_{3}=\sum_{i=1}^{i=n} \Phi_{\mathrm{\kappa} i} l_{i}
$$

$\Phi_{3}$ - the physical deterioration of the building, \%;

$\Phi_{\kappa i}$ - the physical deterioration of an individual structure, element, or system, \%;

$l_{i}$ - coefficient corresponding to the share of the replacement cost of an individual structure, element, or system in the total replacement cost of a building;

$\mathrm{n}$ - the number of individual structures, elements, or systems in a building.

Using the approach described above, we will evaluate an affected reinforced concrete building. Figure 5 shows a building taken as an example.

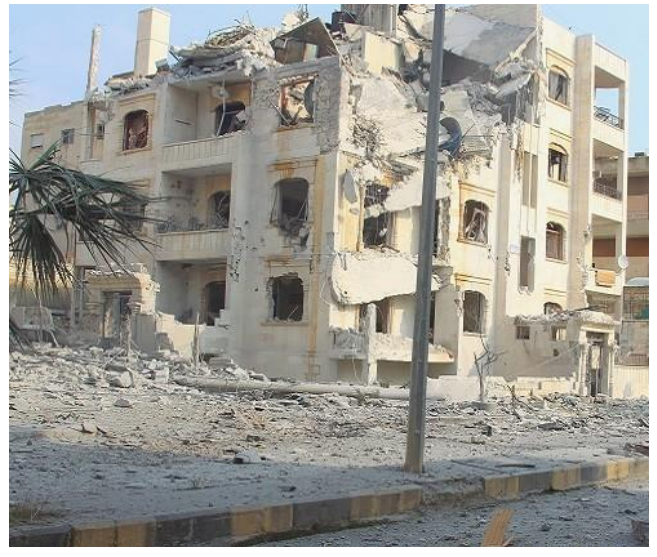

Fig. 5. Affected reinforced concrete building

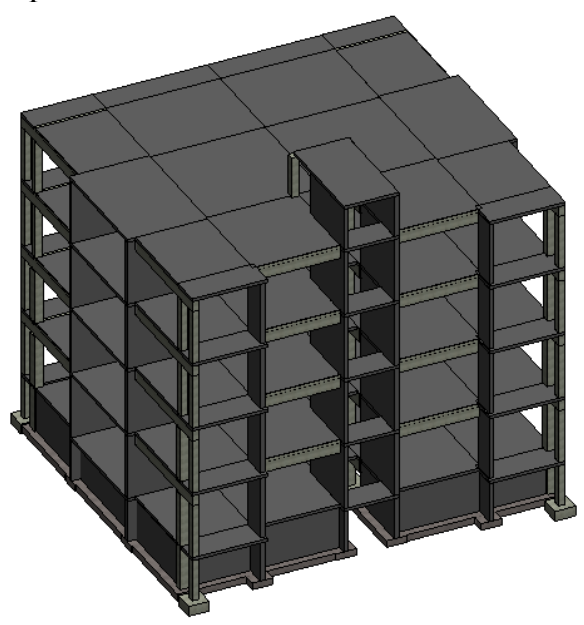

Fig. 6. 3D structural model of the building

In order to fix damages, it is proposed to use BIM technologies. To create an information model of the building, we used the Autodesk Revit and built a 3D structural model of the building, shown in figure 6

To determine the physical deterioration of the building using the formula (2), you will need two add two additional parameters to every structural element

1- $\Phi_{\kappa i}$ - the physical deterioration of an individual structure, element or system, $\%$; which is determined by the formula (1), since the survey of the building condition was not actually carried out, it is impossible to perform calculations using the formula (1), so each structural element was assigned a percentage of physical damage by visual parameters

2- $l_{i}$ - a coefficient that corresponds to the percentage of the replacement cost of an individual structure, element, or system in the total replacement cost of a building; determining the value of this coefficient is a separate topic, so it was set to 1 .

3- New parameters were added to each building element in the model, corresponding to each of the above parameters $\left(\Phi_{\mathrm{\kappa} i}\right.$ :the element's physical wear rate) and $\left(l_{i}\right.$ : the element's significance coefficient) as shown in figure 7 


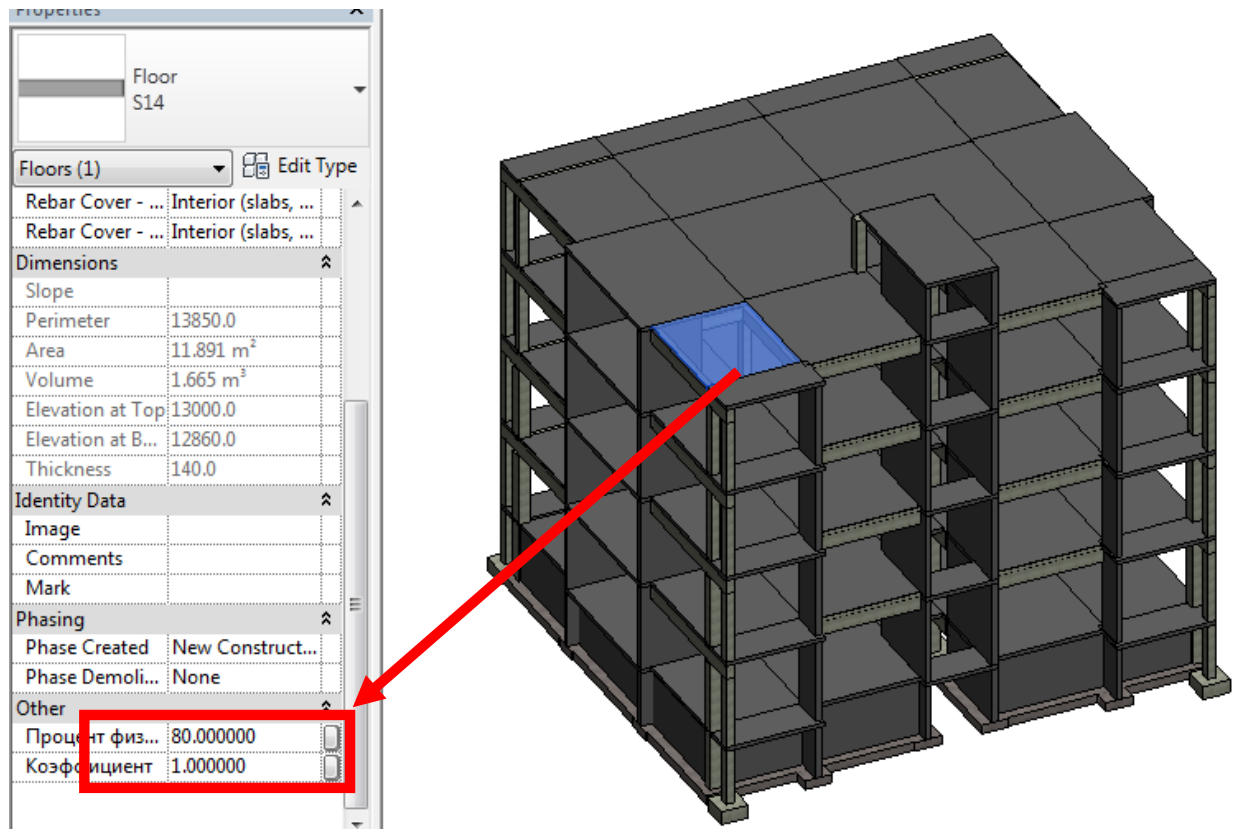

Fig. 7. Added parameters to building's elements

The calculation of physical damage to the building based on the information model using the formula (2) was performed using "Dynamo" using a specially developed calculation algorithm Fig. 8

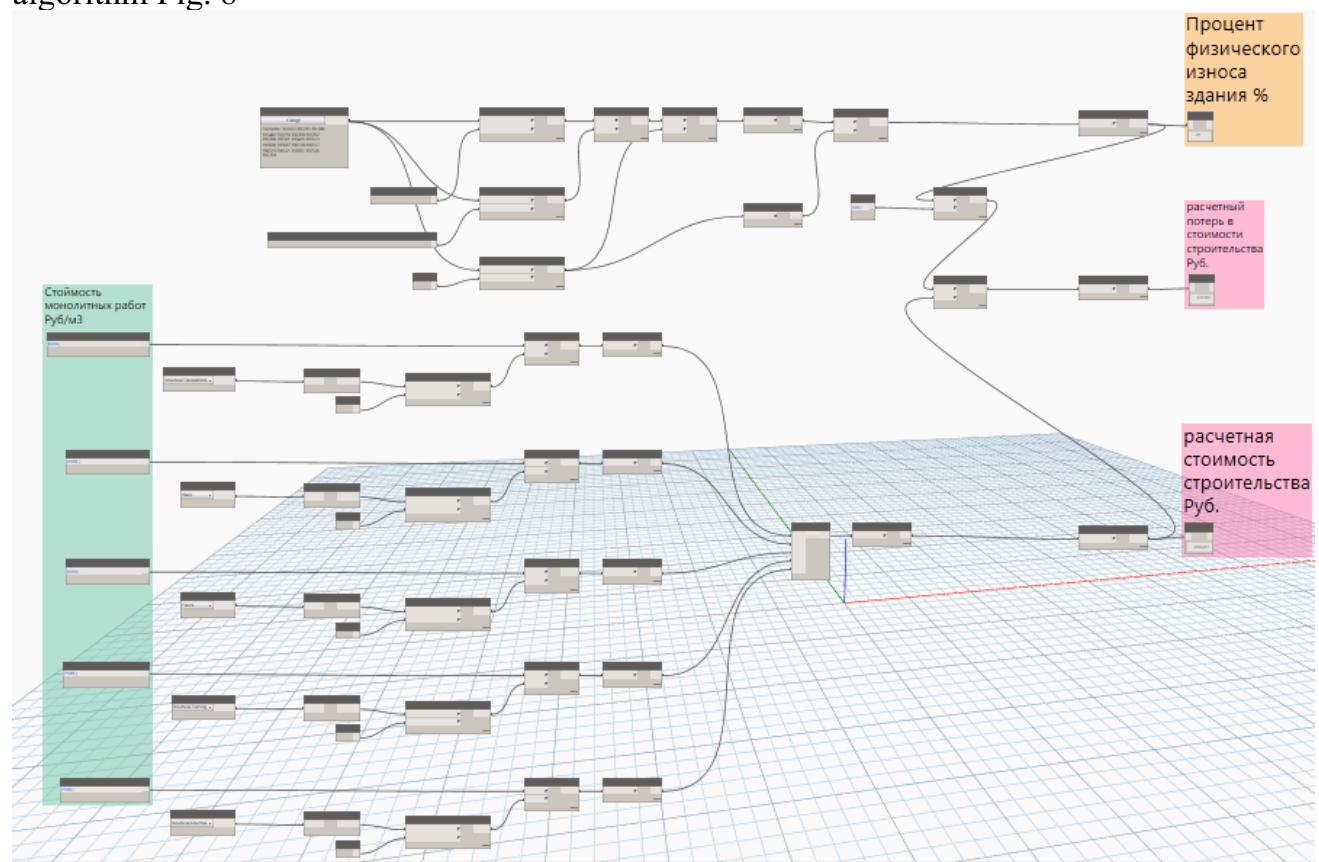

Fig. 8. The calculation algorithm in Dynamo 


\section{Research result}

As a result of the research, an algorithm was developed for generating tables of physical damage to each structure and each element of the building with reference to the 3D model of the building and highlighting the degree of damage to each structure in color. Using the filter function in Revit, you can display physical damage in a color scale, as shown in figure 9, and control the display by percentage of physical damage in figure 10

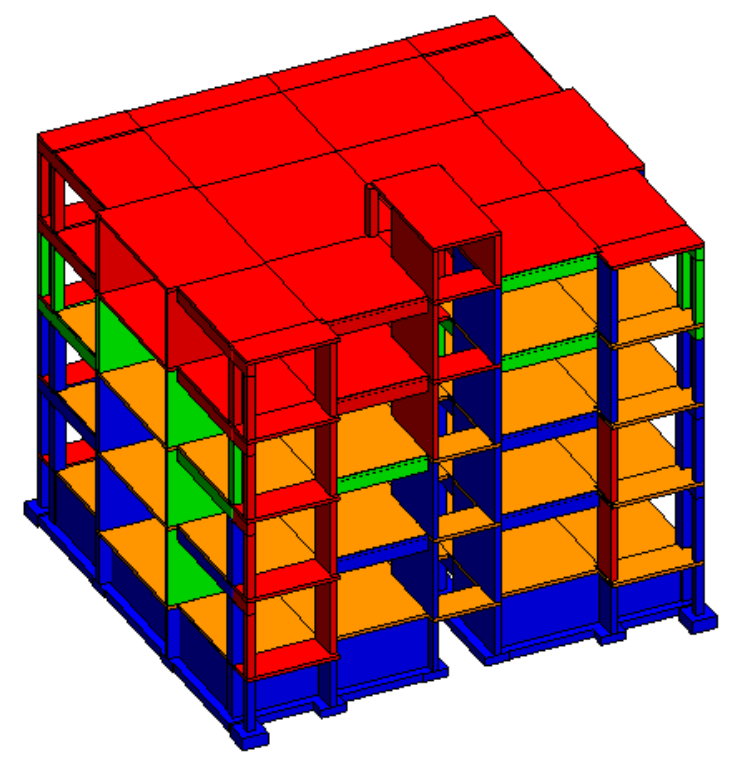

Fig. 9. a color scale of physical deterioration of building's elements
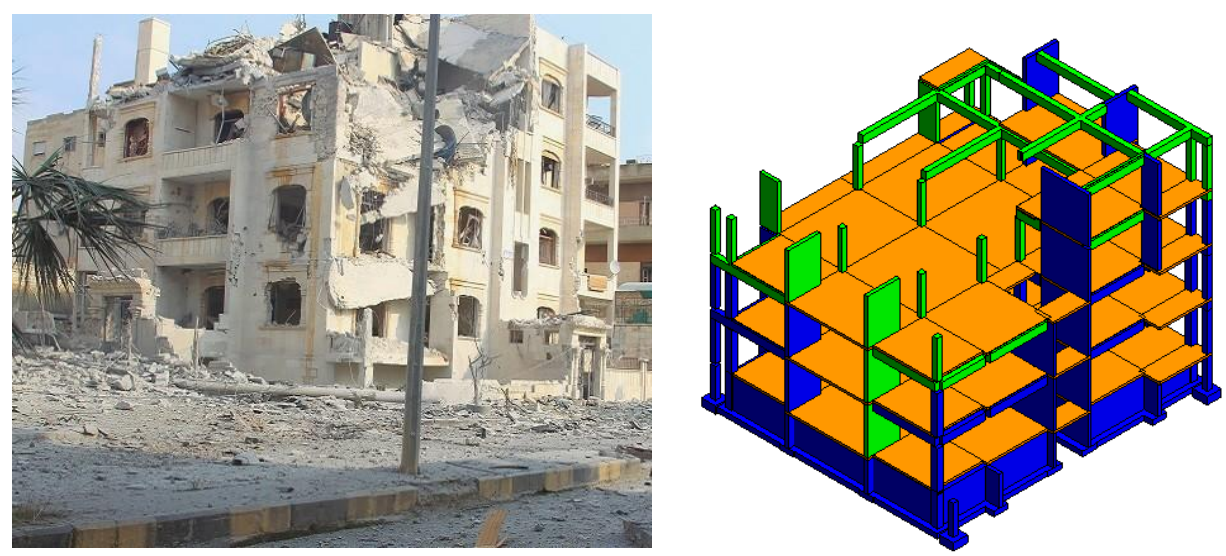

Fig. 10. a comparison of real building with the BIM model

The proposed approach also allows determining the cost and timing of rehabilitation work and making decisions about the feasibility of their implementation. The estimated cost of restoration work is determined by multiplying the number of units of each element by the cost of building a unit, the unit of measurement in our case is taken as a cubic meter. It should be noted that other costs, such as legal, organizational, and engineering costs, should also be included in the calculation of rehabilitation costs. 


\section{Conclusions}

The use of BIM technologies makes it possible, based on a comprehensive information model of a damaged building, to conduct its automated assessment in order to make decisions about the possibility and economic feasibility of its rehabilitation.

The application of the proposed approach significantly facilitates the process of assessing the condition of buildings in comparison with traditional assessment methods and improves the accuracy of data analysis when making complex decisions about the restoration of individual construction building, as well as blocks and neighborhoods during large-scale surveys.

The construction of such models will prepare the basis for automated formation of plans for further rehabilitation activities with the objects under consideration based on the results of analysis of the collected data on buildings.

To improve the accuracy of the proposed approach and achieve the best results, we suggest:

Comprehensive analysis and development of complex methods for determining the cost of both existing structures in an existing building and the cost of their rehabilitation.

Consider methods for determining the element significance coefficient, considering all the factors that affect the operational reliability of the structure.

\section{References}

1. Dmitrieva I.S., Gariaev N.A. Application of simulation modeling for the analysis of architectural and planning solutions for unique objects. In the collection: information systems, technologies and automation in construction. Electronic resource: collection of scientific papers of the Department of ISTAS NRU MGSU. Moscow, 2015.S. 56-60.

2. Gariaev N.A., Gariaeva V.V., Rybina A.V. Development of a simulation model for the analysis of design solutions for remote construction objects from the point of view of providing building materials and structures. Scientific Review. 2015. No. 13. S. $395-$ 398.

3. Garyaev N.A. Design and analysis of information model hotel complex. MATEC Web of Conferences 2016. C. 06007.

4. Garyaev N.A. Geographically distributed learning network construction industry. Computing in Civil and Building Engineering Proceedings 2014 International Conference. 2014. C. 1578-1585.

5. Garyaev N.A., Gagarin P.V. Modern computational modeling as a stage in the development of the design process. MGSU Bulletin. 2009. No. S1. S. 186-187.

6. Garyaev N.A., Krasnoshchekova A.I., Knyazev A.A. Analysis of the risks arising from the implementation of BIM-technologies in construction organizations. BST: Construction Technique Bulletin. 2018. No. 7 (1007). S. 58-61.

7. Garyaev N.A., Rybina A.V. Simulation model of material and technical support of construction objects. System technologies. 2018. No. 1 (26). S. 142-150.

8. Garyaev P.N. Computer-aided zoning and urban planning. Computing in Civil and Building Engineering Proceedings 2014 International Conference. 2014. C. 1618-1625.

9. Garyaeva V.V. Application of BIM modeling for the organization of collective work on a construction project/ MATEC Web of Conferences 2018. C. 05025. 
10. Garyaeva V.V., Garyaev N.A. Integrated assessment of the technical condition of the housing projects on the basis of computer technology. Computing in Civil and Building Engineering Proceedings 2014 International Conference. 2014. C. 1336-1343.

11. Ginzburg A.V., Baranova O.M., Blokhina N.S., Volkov A.A., Gariaev N.A., Ginzburg V.M., Ignatov V.P., Ignatova E.V., Istomin B.S., Kagan P.B., Kitaytseva E.Kh., Kulikov V.G., Sinenko S.A. Design automation systems in construction Moscow, 2014.

12. Shaposhnikov N.N., Kulikov V.G., Gariaev N.A. Representation of invariant materials by creep and relaxation functions. Monograph / Moscow, 2011.

13. VSN 53-86 (p) Rules for assessing the physical deterioration of residential buildings 